\title{
O perfil dos docentes do colégio militar de Santa Maria - RS
}

\author{
Emerson Hartmann \\ Universidade Franciscana - UFN, Brasil \\ Colégio Militar de Santa Maria \\ Elsbeth Léia Spode Becker \\ Universidade Franciscana - UFN, Brasil
}

\section{RESUMO}

Os colégios militares possuem, em sua estrutura funcional, diferentes perfis docentes com carreiras distintas, legislações próprias e expectativas e remunerações diversas. Os diversos perfis docentes, no contexto dos colégios militares, surgem a partir dos diferentes processos formativos que os professores realizam em sua trajetória profissional. Os processos formativos, tanto iniciais quanto ao longo da atividade profissional, são de fundamental importância para a constituição do docente e o exercício de sua prática. Essa formação acontece de maneira fundamental no próprio ambiente escolar em ação conjunta com os docentes e a gestão. Este artigo tem por objetivo principal descrever os principais perfis docentes existentes no Colégio Militar de Santa Maria, Rio Grande do Sul, Brasil. Assim, por meio de uma pesquisa documental e bibliográfica, de abordagem quali/quantitativa, buscou-se elaborar uma construção teórica acerca da relação entre formação e perfil docentes e, também, traçou-se as principais características dos quatro perfis docentes do Colégio Militar de Santa Maria (CMSM). Globalmente sustenta-se a reflexão de Monteiro (2015) de que as qualidades pessoais afetivas e morais devem ser mantidas durante a vida profissional e aprimoradas pela formação profissional. Nesse sentido, em termos de resultados, pôde-se apresentar a distribuição dos profissionais dentro da organização da Divisão de Ensino do Colégio Militar de Santa Maria e inferir que a existência de diferentes perfis no CMSM, com planos de carreira e expectativas diferenciadas, permite que ocorra uma interligação de saberes e conhecimentos diferenciados, bem como um dos princípios fundamentais dentro da profissão docente que é a formação na própria prática dentro da Escola. Como consequência, é possível que o convívio entre os diferentes perfis possa, mesmo que em alguns momentos, criar conflitos e tensões, permitir processos de formação mais próximos da realidade, pois o gerenciamento de conflitos, a capacidade de adaptação e a superação de momentos de instabilidade são hoje inerentes ao trabalho docente.

PALAVRAS-CHAVE: Formação de professores. Perfil docente. Colégio Militar.

\section{PROFILE OF TEACHERS OF SANTA MARIA MILITARY SCHOOL - RS}

\begin{abstract}
Military Schools have, in their functional structure, different teaching profiles and distinct careers, each one with their own legislations, diverse expectations and remunerations. In this context, different teaching profiles emerge from different formative processes, which teachers carry out in their professional trajectory. The formative processes both initial and throughout professional activity are of fundamental importance for teachers' formation and the exercise of their practice. This formation happens in a fundamental way in the school environment
\end{abstract}


itself in joint action with teachers and school management. The main objective of this article is to describe the main teaching profiles in the Santa Maria Military School, Rio Grande do Sul, Brazil. Documental and bibliographical research with a qualitative / quantitative approach was used to elaborate a theoretical construction about the relation between formation and teacher profile and also the main characteristics of four teaching profiles of Santa Maria Military School (CMSM). Overall Monteiro's (2015) reflection supports that personal affective and moral qualities should be maintained during the professional life and improved by the professional formation. In this sense, in terms of results, it was possible to present the distribution of professionals within the organization of the Teaching Division of Santa Maria Military College and infer that the existence of different profiles in the CMSM, with different career plans and expectations, enable an interconnection of different understanding and knowledge, as well as one of the fundamental principles within the teaching profession that is the formation in the own practice within the school. Consequently, it is possible that the interaction between the different profiles can, even at times, create conflicts and tensions, and allow formation processes closer to reality, because conflict management, adaptability and the capacity of overcoming moments of instability are current attributes inherent in teaching work.

KEYWORDS: Teacher training. Teaching profile. Military school.

\section{EL PERFIL DE LOS DOCENTES DEL COLEGIO MILITAR DE SANTA MARIA-RS}

\section{RESUMEN}

Los Colegios Militares poseen, en su estructura funcional, diferentes perfiles docentes, con carreras distintas, legislaciones propias y expectativas y remuneraciones diversas. Los diversos perfiles docentes, en el contexto de los colegios militares, surgen a partir de los diferentes procesos formativos, los cuales los profesores realizan en su trayectoria profesional. Los procesos formativos, tanto iniciales como a lo largo de la actividad profesional, son de fundamental importancia para la constitución del docente y el ejercicio de su práctica. Esta formación ocurre de manera fundamental en el propio ambiente escolar en acción conjunta con los docentes y la gestión. Este artículo tiene por objetivo principal describir los principales perfiles docentes existentes en el Colegio Militar de Santa María, Rio Grande do Sul, Brasil. Así, por medio de una investigación documental y bibliográfica, de abordaje cuali/ cuantitativa, se buscó elaborar una construcción teórica acerca de la relación entre formación y perfil docente y, también, se trazó las principales características de los cuatro perfiles docentes del Colegio Militar de Santa María (CMSM). En general se sostiene la reflexión de Monteiro (2015) de que las cualidades personales afectivas y morales deben ser mantenidas durante la vida profesional y perfeccionadas por la formación profesional. En este sentido, en términos de resultados, se pudo presentar la distribución de los profesionales dentro de la organización de la División de Enseñanza del Colegio Militar de Santa María e inferir que la existencia de diferentes perfiles en el CMSM, con planes de carrera y expectativas diferenciadas, se produce una interconexión de saberes y conocimientos diferenciados, así como uno de los principios fundamentales dentro de la profesión docente que es la formación en la propia práctica dentro de la Escuela. Como consecuencia, es posible que la convivencia entre los diferentes perfiles pueda, aunque en algunos momentos, crear conflictos y tensiones, permitir procesos de formación más cercanos a la realidad, pues la gestión de conflictos, la capacidad de adaptación y la superación de momentos de la inestabilidad son hoy inherentes al trabajo docente.

PALABRAS CLAVE: Formación de profesores. Perfil docente. Colegio Militar. 


\section{INTRODUÇÃO}

Em um cenário educacional que convive com a instabilidade, flexibilidade e constantes alterações, é de extrema importância compreender a relação existente entre os processos de formação e os perfis docentes.

O perfil docente aqui é definido pelo segmento profissional em que o professor está inserido, observando suas diferentes trajetórias formativas, formação inicial, experiências docentes, planos de carreira, estrutura remuneratória, legislação a que está submetido e seus direitos e deveres. Tal definição é importante a fim de permitir analisar, por exemplo, as diferentes percepções entre professores civis/militares, temporários/carreira ou pertencentes ao magistério/linha bélica.

Os ambientes escolares formais convivem com a inclusão de novos perfis discentes, oriundos da inclusão escolar em massa da população brasileira, porém os corpos docentes também se diversificaram, mudando a imagem de um corpo docente homogêneo, único e padronizado.

Tal fato permite a oportunidade de formação na própria escola, pois o convívio entre profissionais com diferentes trajetórias formativas, se torna um grande cenário de enriquecimento e aprendizagem, no entanto, há de se esperar que essas diferenças possam também resultar em conflitos, questionamentos e embates.

Os colégios militares têm, por característica histórica, a diversidade de perfis docentes; sendo assim, o Colégio Militar de Santa Maria, Rio Grande do Sul, Brasil, apesar de possuir uma trajetória relativamente nova, convive, desde a sua fundação até os dias atuais, com diferentes perfis docentes e com as consequências dessa estruturação.

Sob esse aspecto, torna-se significativo descrever, analisar e refletir sobre o perfil docente recorrendo simultaneamente ao contributo de alguns autores (MONTEIRO, 2015; NÓVOA 2014 e TARDIF 2007). É importante acrescentar, que esta reflexão também está alicerçada em análise documental (Normas de Planejamento Escolar, Estatuto dos Militares, Instruções Gerais para o Ingresso e a Carreira do Pessoal Docente Civil do Exército e a Lei de Criação do Quadro Complementar de Oficiais), procedendo à análise dos referidos referenciais, tentando identificar os reptos colocados à profissão professor, concordando que os diferentes perfis docentes no Sistema Colégio Militar do Brasil (SCMB) é complexo e exige, da gestão, o saber de gerenciar o trabalho e as peculiaridades dos diversos perfis docentes. É, portanto, vital que se reflita em qualidade no ensino e oportunidades para formação dos professores na prática diária dentro das escolas. 
Neste artigo, o principal objetivo é descrever, por meio de uma pesquisa documental e bibliográfica, os principais perfis docentes existentes no Colégio Militar de Santa Maria, Rio Grande do Sul, Brasil. Buscou-se, portanto, elaborar uma construção teórica acerca da relação entre formação e perfil docente e, também, traçou-se as principais características dos quatro perfis docentes do Colégio Militar de Santa Maria (CMSM).

Com este intuito, o artigo encontra-se organizado em introdução, metodologia e três pontos e termina com as considerações finais que visam sensibilizar para novas condições ao exercício profissional. Genericamente no ponto I, intitulado "Formação de professores e prática docente", são tratados temas inerentes à formação inicial, formação dentro do ambiente escolar, a realidade educacional atual e interação entre processos formativos e perfil docente. No ponto II, denominado "Perfis Docentes nos Colégios Militares do Brasil", são abordadas as características básicas dos perfis docentes civis e militares. Por último, no ponto III, encontra-se explicitado os "Perfis docentes do Colégio Militar de Santa Maria" e um conjunto de descrições quantitativas acompanhado da descrição das características do perfil.

\section{METODOLOGIA}

Os colégios militares possuem, em sua estrutura funcional, diferentes perfis docentes, com carreiras distintas, legislações próprias e expectativas e remunerações diversas.

Nesta pesquisa, buscou-se elaborar uma construção teórica acerca da relação entre formação e perfil docentes e, também, traçou-se as principais características dos quatro perfis docentes do Colégio Militar de Santa Maria (CMSM). Os quatro perfis docentes analisados foram: Perfil 1. Militares do Quadro Complementar de Oficiais - QCO; Perfil 2. Professores Ensino Básico Técnico Tecnológico- EBTT; Perfil 3. Militares Oficiais Técnicos Temporários - OTT; Perfil 4. Militares do Quadro Auxiliar de Oficiais/Subtenente/Sargento.

A pesquisa foi de abordagem qualiquantitativa, com procedimentos metodológicos baseados em pesquisas bibliográficas acerca da formação docente e na análise documental das Normas de Planejamento e Gestão Escolar do Sistema Colégio Militar.

No primeiro momento, foi realizada a construção teórica acerca da relação entre formação e perfil e, no segundo momento, evidenciou-se as principais características dos perfis docentes do Colégio Militar de Santa Maria (CMSM) e a distribuição dos profissionais dentro da organização da Divisão de Ensino do Colégio Militar de Santa Maria, bem como a discussão à luz das legislações que regem cada um dos quatro perfis docentes. 


\title{
3 FORMAÇÃO DE PROFESSORES E PERFIL DOCENTE
}

Aos docentes, é atribuída, de forma geral, a responsabilidade pela excelência ou fracasso do ensino das instituições escolares. Segundo Nóvoa (1999, p. 3),

\begin{abstract}
Por um lado, os professores são olhados com desconfiança, acusados de serem profissionais medíocres e de terem uma formação deficiente, por outro lado, são bombardeados com uma retórica cada vez mais abundante que os considera elementos essenciais para a melhoria da qualidade de ensino e para o progresso social e cultural.
\end{abstract}

Nos colégios militares, da mesma forma, existe, dentro do próprio Sistema Colégio Militar, do Exército e do senso comum, a visão de que um dos principais motivos de reconhecimento e êxito do processo educacional é um corpo docente qualificado.

Para Monteiro (2015, p. 285), "Selecionar, formar, tratar e confiar em professores como profissionais é essencial para elevar a qualidade da profissão e melhorar a qualidade da educação". Portanto, a relação entre professor e qualidade educacional é direta, sendo de fundamental importância reconhecer que diferentes processos formativos resultarão em perfis docentes distintos.

A docência exige uma formação acadêmica sólida, constante busca de aperfeiçoamento, pesquisa, capacidade de alinhar conhecimentos teóricos à prática e capacidade de constante adaptação às mudanças às quais a sociedade e os alunos são expostos.

Conforme Monteiro (2015, p. 152)

As qualidades pessoais que a profissão docente requer são qualidades afetivas, morais, intelectuais, de amabilidade, serenidade, relacionalidade, acolhimento da alteridade e abertura à diversidade, de rigor e utopia, que devem ser tidas em conta nos critérios de acesso à profissão e cultivadas durante a preparação para o seu exercício.

Portanto, os processos formativos, tanto iniciais quanto ao longo de sua atividade profissional, são de fundamental importância para a constituição do docente e o exercício de sua prática.

Embora não detenha a exclusividade da formação do docente e da definição de seu perfil profissional, é válido lembrar o que De Paulo (2016, p.8) ressalta: "a formação inicial, sem dúvida alguma, tem papel de destaque na construção dos saberes docentes que se manifestam no ato de ensinar".

Ao pensar em um corpo docente, não se pode imaginá-lo em uniformidade e sim em diversidade tanto de concepções de ensino quanto de valores pessoais, que estão relacionados diretamente às experiências individuais. Para Zeichner (1993 p. 23) 
Muito do ensino está enraizado em quem nós somos e como nós percebemos o mundo. [...] Então, voltamos nossa atenção às crenças e entendimento dos professores e como entender a relação entre esses entendimentos e suas práticas, atuais ou prováveis.

A formação docente, suas vivências e experiências fazem o professor possuir concepções de ensino inerentes a sua trajetória profissional, portanto, em um ambiente escolar onde convivem diferentes perfis de professores, existirão diferentes concepções de ensino.

O ambiente escolar é influenciado diretamente pela ação de seus professores, quanto maior diversidade, diferentes origens e expectativas quanto à carreira docente, maiores serão as possibilidades de, em um mesmo ambiente educacional e dentro de uma mesma proposta pedagógica, ocorrerem formas diferentes de ensinar, pois, para Tardif (2007, p. 145), "todo professor transpõe para a sua prática aquilo que é como pessoa”.

As ações docentes refletem seus valores, sua formação e também seus objetivos na sua prática diária. Embora cada escola possua sua proposta pedagógica, critérios avaliativos, princípios educacionais e até mesmo mecanismos de seleção de docentes, isto não eliminará a existência de diferentes perfis docentes que atuarão em um mesmo ambiente escolar e, muitas vezes, com o mesmo grupo de alunos, o que é explicado por Lima e Gomes (2012, p. 207), "Quando o professor fecha a porta da sala de aula, suas práticas são reveladoras de um conjunto de crenças e convicções que vão além das intenções assinaladas no plano formal".

Nóvoa (2009, p. 6) acredita que “[...] o professor é a pessoa, e que a pessoa é o professor. Que é impossível separar as dimensões pessoais e profissionais. Que ensinamos aquilo que somos e que, naquilo que somos, se encontra muito daquilo que ensinamos".

Portanto, haverá sempre características pessoais na ação docente e no processo de ensino.

Em decorrência dessa característica fundamental, por si só já encontraremos diferentes perfis de docentes, os quais, somados a outros aspectos como idade, formação, concepção ideológica, planos de carreira, estrutura remuneratória, estabilidade ou não, locais de trabalho e expectativas profissionais, contribuirão para convivência de diferentes perfis atuando dentro de uma mesma escola e, muitas vezes, de formas totalmente diversas.

O ambiente escolar não é apenas um local onde se busca a formação do estudante, mas, conforme Nogaro e Cerutti (2016, p. 147), é onde "o educador constrói-se retoricamente no processo no qual está inserido". Ou seja, é também um espaço de formação e transformação do professor, que, no convívio com diferentes perfis profissionais, também se transforma. 
Dentro desse ambiente escolar, urge a necessidade da ampliação do fazer pedagógico coletivo, a fim de que possamos encontrar, conforme Nóvoa (1999, p.8), "espaços de debate, de planificação e de análise, que acentuem a troca e a colaboração entre os professores".

Muitas vezes, como salienta Nóvoa (2014, p. 21), "A afirmação profissional dos professores é um percurso repleto de lutas e de conflitos, de hesitações e recuos". Não há professor que não encontrará dificuldades, que mudará sua forma de exercer a docência, e que, por consequência, sofrerá de alguma forma um processo formativo ao longo da atividade profissional, processo esse intimamente relacionado ao seu perfil docente.

Esses obstáculos ou adversidades são inerentes à atividade docente, mas, como salientam Nogaro e Cerutti (2016, p.94), "A docência constitui uma profissão carregada de paradoxos, expectativas e desafios, mas também repleta de esperanças e possibilidades".

Para Lelis (2008, p. 59), "deve-se respeitar a experiência do mestre e levar em consideração os processos dinâmicos e interativos, de formação contínua, vividos em espaços concretos pelo coletivo que constitui esse grupo profissional". A própria escola é o ambiente de formação, o fazer pedagógico em coletividade torna-se um espaço de formação, bem como as relações sociais que são estabelecidas no dia a dia da rotina escolar.

Ressaltando as palavras de Freire (1996, p. 22), "o trabalho do professor é o trabalho do professor com os alunos e não do professor consigo mesmo". O professor não vive, trabalha ou se forma individualmente e sim na prática diária da docência e das relações sociais que mantém com seus alunos, colegas e demais agentes educacionais.

A realidade educacional do século XXI é bastante complexa, heterogênea, difusa e apresenta, aos professores, inúmeros desafios que vão muito além da reprodução da bagagem cultural. Várias atribuições são delegadas à escola e ao corpo docente, grande parte destas de cunho social, moral e até mesmo de caráter econômico.

Para Libâneo (2010, p. 20),

Os educadores, tanto os que se dedicam à pesquisa quanto os envolvidos diretamente na atividade docente, enfrentam uma realidade educativa imersa em perplexidades, crises, incertezas, pressões sociais e econômicas, relativismo moral, dissoluções de crenças e utopias.

Em uma sociedade repleta de instabilidade, relatividade e fluidez, em que conforme Nogaro e Cerutti (2016, p. 65), "nada do que nos cerca é feito para durar, para ser 'sólido"”. É o mundo das incertezas, das incompreensões, do individualismo, do egoísmo". Nesse contexto, a atividade docente defronta-se com a necessidade da prática pautada fortemente em princípios éticos, entrelaçados ao perfil e à formação dos professores. 
Nesse cenário de extrema volatilidade, é válido ressaltar o descrito na pesquisa realizada por Hartmann; Becker (2017, p. 74):

A busca por práticas docentes coerentes com o cenário atual, tanto no campo educacional, econômico, social e informacional, é de fundamental importância para que as escolas e os sistemas de ensino possam atender às novas demandas e expectativas dos alunos e da sociedade.

Outra característica fundamental de nosso tempo é a grande velocidade e quantidade de informações que são geradas, oriundas e aliadas à imensa capacidade de inovação tecnológica em campos como o da comunicação e da tecnologia da informação. Para Benvenutti (2014, p. 103),

Como indivíduos pertencentes a um coletivo que cada vez mais se organiza sob o intermédio das tecnologias, o docente deve estar criticamente aberto à participação, ao trabalho coletivo e, sobretudo, à diversidade cultural.

Esse novo cenário está intimamente ligado a novos perfis discentes, por consequência da necessidade constante de adaptação e mudança dos professores a fïm de acompanharem essa nova realidade.

Para Rauber (2004, p. 9),

Perante as transformações e inovações tecnológicas que na atualidade se processam de forma cada vez mais rápida, exigindo das pessoas novas habilidades e novos conhecimentos, muitos ainda não dominados, é oportuno e nunca demais lembrar que o conhecimento e a capacidade de lidar com inúmeras informações se torna cada vez mais uma exigência a todos os profissionais, em particular aos profissionais da educação.

Fica claro que existem, no contexto atual, novas demandas/necessidades a todo professor que queira exercer sua atividade em consonância com a realidade do século XXI, dentre as quais, a constante necessidade de aperfeiçoamento, pesquisa e formação, a fim de impedir a perda da importância e do papel do professor no processo de ensino.

A sociedade vive em um ritmo acelerado e de constantes mudanças, trazendo ao dia a dia escolar a necessidade e a cobrança por transformações e adaptações, que estão diretamente relacionadas ao trabalho do professor.

Para Nóvoa (2009, p. 2):

A educação vive um tempo de grandes incertezas e de muitas perplexidades. Sentimos a necessidade de mudança, mas nem sempre conseguimos definirlhe o rumo. Há um excesso de discursos, redundantes e repetitivos, que se traduz numa pobreza de práticas.

A necessidade de mudança é um "mantra" que se instalou dentro da academia, dos setores que gerenciam as políticas educacionais e também dentro dos ambientes escolares. 
Porém a direção a ser tomada, as medidas mais adequadas, a forma e a velocidade das transformações estão em um patamar muito inferior à realidade do que as transformações acontecem.

Para tanto, conforme Nóvoa (1999, p.10),

É impossível imaginar alguma mudança que não passe pela formação de professores. Não estou a falar de mais um "programa de formação" a juntar a tantos outros que todos os dias são lançados. Quero dizer, sim, da necessidade de uma outra concepção, que situe o desenvolvimento pessoal e profissional dos professores ao longo dos diferentes ciclos da sua vida.

Percebe-se, portanto, que a saída apresentada para o surgimento desse novo perfil docente, além de enfrentar os inúmeros desafios e o novo ambiente educacional, é a formação docente.

Para Ferry (2004), há uma relação direta entre a vida profissional e a formação, sendo situações contínuas e integradas e, por isso, destaca a importância da reflexão constante sobre a prática docente.

É válido ressaltar que esses processos formativos têm de estar inseridos nos programas de formação de professores, sua chegada às escolas e principalmente ao longo de toda sua atividade docente, pois, conforme Freire (1996, p. 34), "Este é um saber fundante da nossa prática educativa, da formação docente, o da nossa inconclusão assumida".

Existe a necessidade e o desejo desse professor com perfil ativo, crítico, atuante para além da educação puramente "bancária" ${ }^{1}$ " relatada por Freire (1987), pois uma prática docente, pautada por transmissão e reprodução, não consegue mais atender à demanda e às expectativas dos alunos e da própria sociedade.

Segundo Lawn (1991, p. 39, apud NÓVOA, 2014, p. 26), ’Eu quero professores que não se limitem a imitar outros professores, mas que se comprometam (e reflitam) na educação das crianças numa nova sociedade".

Espera-se, portanto, um novo perfil de profissional docente, que seja capaz de se posicionar frente à realidade em que está inserido, seja dinâmico, aberto às constantes e novas demandas que são e serão trazidas por seus alunos, pelos colegas professores e pela comunidade escolar e, principalmente, que esteja, durante toda a sua docência, em um processo de constante formação.

Conforme Nogaro e Cerutti (2016, p. 121):

\footnotetext{
1“Em lugar de comunicar-se, o educador faz "comunicados" e depósitos que os educandos, meras incidências, recebem pacientemente, memorizam e repetem" (FREIRE, 1987, p. 33).
} 
É neste contexto que urge preparar o educador para uma prática reflexiva à inovação e à cooperação. Sendo ele um profissional que está ligado à formação da consciência do ser humano, deve, indubitavelmente, ser uma pessoa de visão aberta, dinâmica e um profundo questionador do seu fazer e da realidade à sua volta.

Uma das características necessárias ao professor do século XXI é a capacidade de se relacionar não somente com seus alunos, mas com os demais professores, gestores e comunidade escolar, sendo essa capacidade de relacionamento uma condição indispensável dentro do perfil docente.

Nessa direção, torna-se fundamental perceber, conforme Freire (1996, p.25), que "nenhuma formação ocorre de forma isolada, tão pouco definitiva em um espaço de diferenças, quem se forma e se re-forma ao formar".

A formação deixa de ser exclusividade do período universitário, quer seja da graduação ou da pós-graduação nos mais diversos níveis, e também não se restringe a momentos isolados e restritos de atualização dentro dos calendários escolares das instituições de ensino. A formação ocorre no próprio dia a dia, em coletividade e inserida na própria prática docente e no exercício da profissão.

Segundo Batista (2006, p. 12)

Portanto, é importante que a escola possa ser vista não somente como lugar em que se ensina, mas sobretudo, onde se aprende. Por outro lado, precisa-se conceber o professor enquanto sujeito que, sendo social é também individual; quer dizer, a formação pertence ao próprio sujeito, implicando investimento pessoal. Entende-se que a formação é um processo contínuo, pessoal e coletivo.

Sendo a escola um local de formação, a própria docência se torna um processo formativo, pois está diretamente relacionada à prática do professor e, também, à sua trajetória e perfil profissional. Há de se concordar com a afirmação de Lima e Gomes (2012), ao dizerem que não se pode prescindir da docência como base para formação de professores.

Ao se desejar um perfil docente que possua capacidade de análise crítica, constante inquietação intelectual, ética e moral a respeito do exercício da atividade docente, é extremamente coerente o que Freire (1996, p .22) assinala, “é pensando criticamente a prática de hoje ou de ontem que se pode melhorar a próxima prática".

No contexto de uma formação na própria ação docente, Rauber (2004, p. 15), afirma que "a prática docente se torna uma fonte de conhecimento seja através da reflexão ou da experimentação".

O questionamento, análise e até mesmo revisão das práticas docentes se tornam um importante instrumento formativo. Para Nóvoa (2007, p. 14), “a formação do professor é, por 
vezes, excessivamente teórica, outras vezes excessivamente metodológica, mas há um déficit de práticas, de refletir sobre as práticas, de trabalhar sobre as práticas, de saber como fazer".

Ao se pensar no tipo de formação docente adequado ou no perfil docente que se espera dos professores nesse século XXI, tem-se diversos caminhos, propostas e referenciais em Nóvoa (2007, p. 18):

Podem inventar tecnologias, serviços, programas, máquinas diversas, umas a distância outras menos, mas nada substitui o bom professor. Nada substitui o bom senso, a capacidade de incentivo e de motivação que só os bons professores conseguem despertar. Nada substitui o encontro humano, a importância do diálogo, a vontade de aprender que só os bons professores conseguem promover. É necessário que tenhamos professores reconhecidos e prestigiados; competentes, e que sejam apoiados no seu trabalho, o apoio da aldeia toda. Isto é, o apoio de toda a sociedade. São esses professores que fazem a diferença. É necessário que eles sejam pessoas de corpo inteiro, que sejam profissionais de corpo inteiro, capazes de se mobilizarem, de mobilizarem seus colegas e mobilizarem a sociedade, apesar de todas as dificuldades.

A prática docente é uma atividade dinâmica, interativa e que necessita de constante diálogo e atualização, a fim de que possa dar conta das inúmeras especificidades da realidade educacional escolar. Para tanto, não há mais espaço para formação exclusivamente durante a realização da graduação ou formações pré-moldadas em momentos isolados da carreira docente e do ano escolar. Há que se permitir e incentivar a formação na ação, ou seja, durante o próprio exercício da docência e do fazer pedagógico na escola.

Ainda é importante ressaltar que cada professor possui suas especificidades, ou seja, possui características que adquiriu através de sua formação inicial, experiências de vida, exercício da profissão docente, do grupo social e profissional em que está inserido e de seus princípios morais e valores éticos. Esse grupo de características vai traçando o perfil docente de cada professor.

A relação entre formação e perfil docentes é direta, saber entender como ocorre esse funcionamento, bem como compreender os diferentes perfis docentes existentes dentro do ambiente escolar é fundamental para execução do ensino, portanto o Sistema Colégio Militar do Brasil (SCMB), que possui vários perfis em seu corpo docente, precisa também ter uma noção clara de quem são os seus professores.

\section{PERFIS DOCENTES DOS COLÉGIOS MILITARES NO BRASIL}

O Sistema Colégio Militar do Brasil possui 13 Colégios Militares (CM), distribuídos em todas as regiões brasileiras, sendo que o primeiro Colégio Militar criado foi o do Rio de Janeiro, em 09 de março de 1889, ainda no Brasil Império. 
Os CM, em alguns casos, possuem uma história centenária, e outros foram criados também ao longo do século XX e até mesmo século XXI. Iniciaram com um corpo docente próprio, o que não significa apenas um perfil docente. No caso do Colégio Militar do Rio de Janeiro, o corpo docente era formado basicamente por dois perfis docentes, os civis e militares. Tal característica básica se manteve por praticamente todos os $\mathrm{CM}$, cujos perfis docentes foram se ampliando com o surgimento de situações específicas como a celebração dos convênios entre o Exército e governos estaduais que resultaram em cedência de professores da rede pública estadual. ${ }^{2}$

A diversidade do perfil docente aumenta com o surgimento dos oficiais professores temporários e da utilização de praças da linha bélica em caráter excepcional atuando como professores. Essa diversidade de perfis tem impacto na execução da proposta pedagógica e nas atividades de ensino, pois um Sistema que possui valores, normas definidas e objetivos que se alinham aos do próprio Exército Brasileiro tem, em seu corpo docente, uma diversidade muito ampla de trajetórias formativas. Importante também destacar que possuem legislações, remuneração, direitos, deveres e expectativas profissionais diferentes, todavia, atuam conjuntamente e sob a mesma proposta pedagógica.

Os professores militares sejam temporários ou de carreira, independentemente do seu posto e graduação, além das funções docentes, estão submetidos a todas as atribuições de um militar do Exército Brasileiro. Para tanto concorrem, por exemplo, a escalas de serviço, processos administrativos, participação em formaturas e demais determinações do Comandante/Diretor do Colégio Militar.

Todos os professores militares possuem habilitação específica para atuarem como docentes e são incentivados pelo Exército Brasileiro a realizarem constantes processos de formação e aperfeiçoamento. Importante ressaltar que sua remuneração está vinculada a seu nível hierárquico e não ao exercício da atividade docente.

Dentro da carreira de professor militar, outra característica marcante é a possibilidade de atuar em diversos Colégios Militares nas mais variadas regiões do País ao longo de sua atividade docente, característica inerente à perspectiva de uma vivência nacional e da necessidade do serviço. Portanto não há um vínculo permanente apenas com um Colégio Militar.

Os professores civis são profissionais da carreira federal de Ensino Básico Técnico e Tecnológico, portanto servidores com estabilidade, remuneração vinculada também à

\footnotetext{
${ }^{2}$ Exemplos como o Colégio Militar de Salvador e Colégio Militar de Curitiba.
} 
titulação o que traz como consequência positiva para os Colégios Militares a permanente busca de aperfeiçoamento e qualificação.

Os professores civis possuem atribuições e direitos diferentes dos militares, seja na questão remuneratória quanto a possibilidades de licença capacitação ou expediente diferenciado. Ainda, se assim o desejarem, passarão todo o seu tempo de exercício profissional apenas em um Colégio Militar.

Neste cenário, o Colégio Militar de Santa Maria (CMSM) também surge com perfis docentes diferenciados, primeiramente, com professores civis cedidos pela rede pública e militares de carreira professores e, posteriormente, incorporando novos perfis, como, por exemplo, os professores civis federais.

\section{PERFIS DOCENTES DO COLÉGIO MILITAR DE SANTA MARIA}

O Colégio Militar de Santa Maria (CMSM) possui, em seu efetivo de professores, um perfil docente diversificado com o qual convivem professores civis, militares, efetivos, temporários e profissionais designados em caráter excepcional. A existência de uma diversidade de trajetórias formativas em um mesmo ambiente escolar é, para Batista (2006), uma oportunidade para a formação coletiva e contínua e, conforme Nogaro e Cerutti (2016), uma circunstância favorável em que o educador se constrói no ambiente em que está inserido.

Os quatro perfis de docentes existentes no CMSM e suas características são apresentados no Quadro 1 a seguir.

Quadro 1: Perfil de docentes do CMSM e suas características.

\begin{tabular}{|l|l|}
\hline \multicolumn{1}{|c|}{ Perfil Docente } & \multicolumn{1}{|c|}{ Características } \\
\hline $\begin{array}{l}\text { Perfil 1: Militares do Quadro } \\
\text { Complementar de Oficiais }-\end{array}$ & $\begin{array}{l}\text { Oficiais de carreira, estabilizados, formação acadêmica } \\
\text { Qespecífica nas respectivas licenciaturas, com postos de } 1^{\circ} \\
\text { tenente a coronel. }\end{array}$ \\
\hline $\begin{array}{l}\text { Perfil 2: Professores Ensino } \\
\text { Básico Técnico Tecnológico- } \\
\text { EBTT }\end{array}$ & $\begin{array}{l}\text { Professores civis, concursados, carreira federal, dedicação } \\
\text { exclusiva e vinculados ao Ministério da Defesa/Comando do } \\
\text { Exército. }\end{array}$ \\
\hline $\begin{array}{l}\text { Perfil 3: Militares Oficiais } \\
\text { Técnicos Temporários }-\end{array}$ & $\begin{array}{l}\text { Oficiais temporários, seleção simplificada, até 08 anos de } \\
\text { Serviço, com postos de aspirante a } 1^{\circ} \text { tenente e possuidores de } \\
\text { habilitação em suas respectivas licenciaturas. }\end{array}$ \\
\hline $\begin{array}{l}\text { Perfil 4: Militares Quadro } \\
\text { Auxiliar de Oficiais/Sub } \\
\text { Tenente/Sargento }\end{array}$ & $\begin{array}{l}\text { Militares de carreira, oriundos da linha bélica, caráter provisório } \\
\text { e excepcional, com habilitação em suas respectivas } \\
\text { licenciaturas, atuando fora da área de formação militar. Com } \\
\text { graduações de sargento até o posto de capitão. }\end{array}$ \\
\hline
\end{tabular}

Fontes: BRASIL (1980), Estatuto dos Militares. BRASIL (2005), Portaria 291 (adaptado por Emerson Hartmann). 


\subsection{Perfil 1 - Militares do Quadro Complementar de Oficiais (QCO)}

O Quadro Complementar de Oficiais (QCO) surge com a edição da Lei Federal $n^{\circ}$ 7.831, de 02 de outubro de 1989, quando são estabelecidos os requisitos para ingresso, postos a serem ocupados e preceitos da nova carreira.

Portanto, o QCO é recente dentro da Força Terrestre, tendo formado sua primeira turma no ano de 1990. Está inserido dentro das atividades-meio, ou seja, não são profissionais formados para o combate, a atividade-fim do Exército e sim profissionais que atuam no apoio especializado a diversos setores da instituição, dentre os quais, a docência nos Colégios Militares.

Dentro de seu efetivo, encontrar-se-ão também professores do sexo feminino ${ }^{3}$ que ingressaram a partir do ano de 1992. O ingresso de integrantes do sexo feminino já constava na Lei de criação do QCO, porém, como destacado no Art. $4^{\circ} \S 3^{\circ}$, havia necessidade de medidas de adaptação ${ }^{4}$ por parte da Administração do Exército, a fim de receber o segmento feminino.

A formação dos integrantes do QCO ocorre na cidade de Salvador- BA, na Escola de Formação Complementar do Exército, onde o curso tem uma duração de 09 meses.

Embora professores, possuem remunerações equivalentes a seus postos militares, bem como estão sujeitos às leis e regulamentos militares, ainda concorrem às escalas de serviço e rotinas administrativas de seus respectivos postos. Importante destacar a possibilidade de serem transferidos dentro do território nacional para qualquer um dos treze Colégios Militares.

A formação acadêmica nas áreas do magistério ocorreu em universidades públicas ou privadas do meio civil, tendo, após ingresso por concurso público, a nível nacional, realizado cursos de formação ou especialização em instituições de ensino militares.

Possuem, dentro do Colégio Militar, atribuições docentes, de chefia e coordenação. Cabe ressaltar que, no contexto atual, os processos de seleção para este quadro são extremamente restritos, inclusive durante alguns anos sem abertura de nenhuma vaga em todo o Brasil. Para exemplificar, o concurso público do ano de 2018 prevê a seleção de apenas

\footnotetext{
${ }^{3}$ De maneira pioneira, pois foram precursoras na entrada de oficiais de carreira no Exército Brasileiro. Seguido em 1997 pelo Instituto de Engenharia Militar do Exército, 2001 pela Escola de Saúde do Exército e em 2017 pela Escola Preparatória do Exército iniciando a formação das primeiras oficiais combatentes do Exército Brasileiro.

${ }^{4}$ Medidas como adequação das instalações físicas, ou seja, vestiários e alojamentos, bem como preparação dos militares que atuariam na formação desse novo perfil profissional. Esse período de adaptação transcorreu durante dois anos.
} 
cinco ${ }^{5}$ profissionais em todo o País, o que vem acarretando a diminuição ${ }^{6}$, no Sistema Colégio Militar e no CMSM, do efetivo deste perfil docente. Fato extremamente complexo e que interferirá diretamente no trabalho dos professores do QCO, foi a publicação no Boletim do Exército no 40/2017, da Portaria no 419 - Estado Maior do Exército, de 06 de outubro de 2017, que criou novos períodos de interstícios para promoção, com diferenças entre profissionais combatentes e integrantes/professores do QCO.

Em um País em que a profissão docente é extremamente degradada e possui poucos atrativos, as palavras de Nóvoa (2007, p. 12) são duras e objetivas:

É também um paradoxo a glorificação da sociedade do conhecimento em contraste com o desprestígio com que são tratados os professores. Como se, por um lado, achássemos que tudo se resolve dentro das escolas e, por outro, achássemos que quem está nas escolas são os profissionais razoavelmente medíocres, que não precisam de grande formação, grandes condições salariais, que qualquer coisa serve para ser professor.

O tratamento diferenciado, com variados tempos para promoção, aliado ao surgimento de um sentimento de exclusão, desprestígio e segregação terão efeitos imediatos e de médio e longo prazos no corpo docente dos Colégios Militares, consequências essas ainda não mensuradas no ensino, mas já presentes no ambiente escolar.

\subsection{Perfil 2 - Professores do Ensino Básico Técnico e Tecnológico (EBTT)}

Os profissionais do Ensino Básico Técnico e Tecnológico (EBTT) são regidos por uma carreira federal pertencente ao Ministério da Educação, mas, administrativamente, são vinculados ao Comando do Exército.

Possuem, dentro do CMSM, atribuições docentes, bem como de coordenadores de disciplina e de coordenadores pedagógicos de ano. Os processos seletivos ocorrem de maneira muito esporádica ${ }^{7}$, sempre abaixo das necessidades e das vagas ${ }^{8}$ existentes.

A solução encontrada pelo CMSM, para recompletar o efetivo docente, vem sendo o uso de processos de redistribuição de professores dos Institutos Federais de Educação, os quais possuem a mesma carreira. Os processos são realizados através de portarias interministeriais do Ministério da Educação e Defesa, o que já permitiu que mais de um terço dos professores EBTT do CMSM tenham sua origem em institutos federais.

\footnotetext{
${ }^{5}$ Dois profissionais de história, um de biologia, que irão para Colégios Militares, um de francês e um de alemão que atuarão em outros estabelecimentos de ensino do Exército.

${ }^{6}$ Decorrente dos pedidos de reserva remunerada (similar aposentadoria), aprovação em concursos públicos fora da Força Terrestre, cota compulsória (aposentadoria proporcional) e pedidos de demissão do serviço ativo.

${ }^{7}$ Nos últimos dez anos, ocorreram dois processos seletivos, sendo ofertadas apenas 05 vagas, 03 de inglês e 02 de biologia.

${ }^{8}$ O CMSM possui um efetivo previsto de 42 professores EBTT.
} 
Os processos de remoção são restritos ao número de vagas existentes no quadro efetivo de profissionais, que se mantém inalterado, mesmo diante do aumento das demandas educacionais, e possuem um trâmite burocrático lento e que exige uma grande demanda de "energia" pelos gestores de ensino.

Válido lembrar que, embora estejam trabalhando dentro de uma unidade militar/colégio, são profissionais civis, com legislação própria.

\subsection{Perfil 3 - Militares Oficiais Técnico Temporários (OTT)}

Militares que passam por seleção simplificada, gerida pela $3^{\text {a }}$ Região Militar ${ }^{9}$, e que, após um breve período ${ }^{10}$ de adaptação militar, são classificados para atuarem como professores no CMSM.

Possuem formação nas áreas específicas de magistério em que atuam, porém, além de serem professores, atuam nas mais diversas atividades militares, quais sejam, atividades de serviço, escalas ou rotinas administrativas do próprio Exército.

Uma característica importante dentro desse perfil é que possui tempo máximo de permanência, o que naturalmente os conduz, durante todo o seu tempo como professores militares, a já buscarem outras atividades, seja pela realização de concursos públicos ou da constante busca por qualificação. Existe uma rotatividade e a instabilidade da renovação anual vinculada à existência de vaga e também ao seu desempenho tanto como militar quanto como professor.

O CMSM ainda possui carência desses profissionais, já que a seleção é externa e nem sempre, dentro do efetivo máximo existente, ocorre o pleno preenchimento das vagas ociosas.

Outra característica deste perfil é que são na maioria profissionais jovens, com pouca experiência docente e que almejam encontrar, para além da atividade no CMSM, uma estabilidade futura.

\subsection{Perfil 4. Militares Quadro Auxiliar de Oficiais/Subtenente/Sargentos}

Este perfil compreende os profissionais oriundos da linha bélica, ou seja, formados para a atividade-fim que é o combate. Todavia, durante suas trajetórias como militares, realizaram formação civil na área de magistério.

\footnotetext{
${ }^{9}$ Grande comando responsável pela seleção, com sede em Porto Alegre.

${ }^{10}$ Formação reduzida de aproximadamente 45 dias, restrita aos fundamentos básicos da vida militar.
} 
Dentro do efetivo do CMSM e demais colégios militares, não há previsão de atuarem como professores, porém o fruto da carência de professores e essa ser uma solução mais rápida e viável foi a saída emergencial encontrada.

São profissionais com bastante experiência militar, estabilizados e voluntários a atuarem em sala de aula, mas com um aspecto a ser destacado: a falta de experiência na atividade docente da educação básica, bem como do real funcionamento do ensino de um colégio militar.

Em grande parte das vezes, são profissionais cedidos por outras organizações militares, o que acarreta constantes trocas e dependência direta de outros comandantes para poderem atuar como professores. Além disso, possuem planos de carreira que fazem com que sejam transferidos com maior frequência.

\section{DISTRIBUIÇÃO DOS PERFIS DOCENTES NO CMSM NAS DIFERENTES ÁREAS DO CONHECIMENTO}

No $2^{\circ}$ semestre do ano letivo de 2017, o efetivo docente do CMSM era de 91 professores, sendo que 10 encontravam-se em atividades de gestão do ensino. O Quadro 2 abaixo apresenta o número de professores, sua formação e suas atribuições de gestão.

Quadro 2: Docentes em atividade de gestão.

\begin{tabular}{|l|c|l|l|}
\hline Gestão & Número & Formação & Atribuição \\
\hline Direção ${ }^{11}$ & 1 & Matemática & Subdiretor \\
\hline Coordenação & 5 & $\begin{array}{l}\text { Geografia, Química, } \\
\text { Biologia e Física (02) }\end{array}$ & $\begin{array}{l}\text { Coordenador Geral; } \\
\text { Auxiliares de Supervisão }\end{array}$ \\
\hline Seção Técnica & 3 & $\begin{array}{l}\text { Geografia, } \\
\text { Matemática e Física }\end{array}$ & $\begin{array}{l}\text { Responsável pela montagem das } \\
\text { avaliações; } \\
\text { Auxiliares }\end{array}$ \\
\hline Seção Psicopedagógica & 1 & Química & Orientadora educacional. \\
\hline
\end{tabular}

Fonte: BRASIL (2017). Normas de Planejamento e Gestão Escolar (adaptado por Hartmann, 2017).

Todas as coordenações de ano escolar são estruturadas a fim de funcionarem dentro do exposto por Tardif (2007) que pressupõe a interatividade como um saber indispensável aos professores.

As séries, as disciplinas, a formação e o perfil dos docentes estão designados nos quadros a seguir. No $6^{\circ}$ ano, as disciplinas, a formação e o perfil dos docentes estão constituídos conforme apresentado no Quadro 3.

\footnotetext{
${ }^{11} \mathrm{O}$ cargo de Diretor de Ensino pertence ao Comandante do CMSM, militar da linha bélica e possuidor do curso de comando da Escola de Comando e Estado Maior do Exército.
} 
Quadro 3: Docentes $6^{\circ}$ ano

\begin{tabular}{|l|l|l|l|l|}
\hline Séries & Disciplina & Formação & Titulação & Perfil \\
\hline $6^{\circ}$ Ano & História & História & Mestre & OTT \\
\hline $6^{\circ}$ Ano & Matemática & Física & Mestre & QCO \\
\hline $6^{\circ}$ Ano & Geografia & Geografia & Graduado & Sgt \\
\hline $6^{\circ}$ Ano & Português & Português & Especialista & OTT \\
\hline $6^{\circ}$ Ano & Ciências Naturais & Ciências Naturais & Doutora & OTT \\
\hline $6^{\circ}$ Ano & Educação Física & Educação Física & Especialista & EBTT \\
\hline $6^{\circ}$ Ano & Inglês & Inglês & Especialista (02) & EBTT/ QAO \\
\hline $6^{\circ}$ Ano & Arte & Arte & Mestre & EBTT \\
\hline
\end{tabular}

Fonte: Hartmann, 2018

Pode-se observar, tanto na distribuição dos docentes do $6^{\circ}$ ano, bem como nos demais anos letivos, uma distribuição heterogênea dos perfis docentes. Tal procedimento visa justamente permitir ampliação das experiências, trocas, interações e proporcionar que a formação ocorra em conjunto com os demais professores.

Há, neste sentido, um alinhamento ao que ressalta Nóvoa (2007, p. 7), quando o autor observa que "a ideia da escola como o lugar da formação dos professores, como o espaço da análise partilhada das práticas, enquanto rotina sistemática de acompanhamento, de supervisão e de reflexão sobre o trabalho docente".

O $7^{\circ}$ ano, as disciplinas, a formação e o perfil dos docentes estão constituídos conforme apresentado no Quadro 4.

Quadro 4: Docentes $7^{\circ}$ ano

\begin{tabular}{|c|c|c|c|c|}
\hline Séries & Disciplina & Formação & Titulação & Perfil \\
\hline $7^{\circ}$ ano & História & História & Mestre & EBTT \\
\hline $7^{\circ}$ ano & Matemática & Matemática & Mestre/Especialista(02) & OTT \\
\hline $7^{\circ}$ ano & Geografia & Geografia & Especialista & OTT \\
\hline $7^{\circ}$ ano & Português & Português & Mestre/Graduado (02) & OTT \\
\hline $7^{\circ}$ ano & Ciências Naturais & Ciências Naturais & Doutora & EBTT \\
\hline $7^{\circ}$ ano & Educação Física & Educação Física & Graduado & QAO \\
\hline $7^{\circ}$ ano & Inglês & Inglês & Mestre & EBTT \\
\hline $7^{\circ}$ ano & Arte & Arte & Mestre & $\begin{array}{l}\text { EBTT (atua também } \\
\text { no } 6^{\circ} \text { ano) }\end{array}$ \\
\hline
\end{tabular}

Fonte: Hartmann, 2018

O $8^{\circ}$ ano, as disciplinas, a formação e o perfil dos docentes estão constituídos conforme apresentado no Quadro 5 a seguir. 
Quadro 5: Docentes $8^{\circ}$ ano

\begin{tabular}{|l|l|l|l|l|}
\hline Séries & Disciplina & Formação & Titulação & Perfil \\
\hline $8^{\circ}$ ano & História & História & Especialista & OTT \\
\hline $8^{\circ}$ ano & Matemática & Matemática & Mestre (02) & OTT/EBTT \\
\hline $8^{\circ}$ ano & Geografia & Geografia & Graduado & Sgt \\
\hline $8^{\circ}$ ano & Português & Português & $\begin{array}{l}\text { Mestrado/ } \\
\text { Especialista(02) }\end{array}$ & OTT/QCO \\
\hline $8^{\circ}$ ano & Ciências Naturais & Ciências Naturais & Doutora & EBTT \\
\hline $8^{\circ}$ ano & Educação Física & Educação Física & Mestre & OTT \\
\hline $8^{\circ}$ ano & Inglês & Inglês & $\begin{array}{l}\text { Mestre/ } \\
\text { Especialista (02) }\end{array}$ & OTT/QCO \\
\hline $8^{\circ}$ ano & $\begin{array}{l}\text { Desenho } \\
\text { Geométrico }\end{array}$ & Matemática & Mestre & OTT \\
\hline
\end{tabular}

Fonte: Hartmann, 2018

O $9^{\circ}$ ano, as disciplinas, a formação e o perfil dos docentes estão constituídos conforme apresentado no Quadro 6.

Quadro 6: Docentes $9^{\circ}$ ano

\begin{tabular}{|l|l|l|l|l|}
\hline Séries & Disciplina & Formação & Titulação & Perfil \\
\hline $9^{\circ}$ ano & História & História & Especialista & EBTT \\
\hline $9^{\circ}$ ano & Matemática & Matemática & Mestre (02) & OTT/QAO \\
\hline $9^{\circ}$ ano & Geografia & Geografia & Especialista & EBTT \\
\hline $9^{\circ}$ ano & Português & Português & Doutora/Especialista(02) & EBTT/ST \\
\hline $9^{\circ}$ ano & Ciências Naturais & Ciências Naturais & Mestre & OTT \\
\hline $9^{\circ}$ ano & Educação Física & Educação Física & Mestre & EBTT \\
\hline $9^{\circ}$ ano & Inglês & Inglês & Mestre & EBTT \\
\hline $9^{\circ}$ ano & $\begin{array}{l}\text { Desenho } \\
\text { Geométrico }\end{array}$ & Matemática & Especialista & QAO \\
\hline
\end{tabular}

Fonte: Hartmann, 2018

O $1^{\circ}$ ano do Ensino Médio, as disciplinas, a formação e o perfil dos docentes estão constituídos conforme apresentado no Quadro 7.

Quadro 7: Docentes $1^{\circ}$ ano

\begin{tabular}{|l|l|l|l|l|}
\hline Séries & Disciplina & Formação & Titulação & Perfil \\
\hline $1^{\circ}$ ano & História & História & Especialista & QCO \\
\hline $1^{\circ}$ ano & Matemática & Matemática & Especialista & EBTT \\
\hline $1^{\circ}$ ano & Geografia & Geografia & Mestre & EBTT \\
\hline $1^{\circ}$ ano & Português & Português & Doutora & EBTT \\
\hline $1^{\circ}$ ano & Biologia & Biologia & Doutora & EBTT \\
\hline $1^{\circ}$ ano & Educação Física & Educação Física & Graduado & Sgt \\
\hline $1^{\circ}$ ano & Espanhol & Espanhol & Mestre & $\begin{array}{l}\text { QCO (atua demais } \\
\text { séries EM) }\end{array}$ \\
\hline $1^{\circ}$ ano & Química & Química & Mestre & EBTT \\
\hline $1^{\circ}$ ano & Literatura & Literatura & Mestre & EBTT \\
\hline $1^{\circ}$ ano & Sociologia & Sociologia & Mestre & Sgt \\
\hline $1^{\circ}$ ano & Física & Física & Doutor & EBTT \\
\hline
\end{tabular}

Fonte: Hartmann, 2018 
HARTMANN, E.; BECKER, E.L.S.

O $2^{\circ}$ ano do Ensino Médio, as disciplinas, a formação e o perfil dos docentes estão constituídos conforme apresentado no Quadro 8.

Quadro 8: Docentes $2^{\circ}$ ano

\begin{tabular}{|l|l|l|l|l|}
\hline Séries & Disciplina & Formação & Titulação & Perfil \\
\hline $2^{\circ}$ ano & História & História & Mestre & $\begin{array}{l}\text { Sgt (atua também como } \\
\text { professor de Sociologia) }\end{array}$ \\
\hline $2^{\circ}$ ano & Matemática & Matemática & Especialista & EBTT \\
\hline $2^{\circ}$ ano & Geografia & Geografia & Mestre & EBTT \\
\hline $2^{\circ}$ ano & Português & Português & Doutora & EBTT \\
\hline $2^{\circ}$ ano & Biologia & Biologia & Mestre & EBTT \\
\hline $2^{\circ}$ ano & Educação Física & Educação Física & Mestre & EBTT \\
\hline $2^{\circ}$ ano & Inglês & Inglês & Mestre & EBTT \\
\hline $2^{\mathbf{o}}$ ano & Química & Química & Doutor & EBTT \\
\hline $2^{\circ}$ ano & Literatura & Literatura & Mestre & $\begin{array}{l}\text { EBTT (atua como profa. do } \\
1^{\circ} \text { ano) }\end{array}$ \\
\hline $2^{\mathbf{o}}$ ano & Sociologia & Sociologia & Graduado & QAO \\
\hline $2^{\circ}$ ano & Física & Física & Mestre & EBTT \\
\hline $2^{\circ}$ ano & Filosofia & Filosofia & Mestre & $\begin{array}{l}\text { OTT (atua em todas as } \\
\text { séries do EM) }\end{array}$ \\
\hline $2^{\circ}$ ano & Arte & Arte & Mestre & EBTT \\
\hline
\end{tabular}

Fonte: Hartmann, 2018

O $3^{\circ}$ ano do Ensino Médio, as disciplinas, a formação e o perfil dos docentes estão constituídos conforme apresentado no Quadro 9.

Quadro 9: Docentes $3^{\circ}$ ano.

\begin{tabular}{|l|l|l|l|l|}
\hline Séries & Disciplina & Formação & Titulação & Perfil \\
\hline $3^{\circ}$ ano & História & História & Mestre & EBTT \\
\hline $3^{\circ}$ ano & Matemática & Matemática & Mestre/Especialista(02) & EBTT/ST \\
\hline $3^{\circ}$ ano & Geografia & Geografia & Especialista & EBTT \\
\hline $3^{\circ}$ ano & Português & Português & Mestre ( 02) & EBTT \\
\hline $3^{\circ}$ ano & Biologia & Biologia & Mestre & EBTT \\
\hline $3^{\circ}$ ano & $\begin{array}{l}\text { Educação } \\
\text { Física }\end{array}$ & Educação Física & Especialista & EBTT \\
\hline $3^{\circ}$ ano & Inglês & Inglês & Mestre & EBTT \\
\hline $3^{\circ}$ Ano & Química & Química & Especialista & QCO \\
\hline $3^{\circ}$ Ano & Literatura & Literatura & Especialista & QCO \\
\hline $3^{\circ}$ Ano & Sociologia & Sociologia & Mestre & $\begin{array}{l}\text { ST (atua também como prof. } \\
1^{\circ} \text { ano) }\end{array}$ \\
\hline $3^{\circ}$ Ano & Física & Física & Mestre & EBTT \\
\hline $3^{\circ}$ Ano & Filosofia & Filosofia & Mestre & $\begin{array}{l}\text { OTT (atua em todas as } \\
\text { séries do Ensino Médio) }\end{array}$ \\
\hline $3^{\circ}$ Ano & Arte & Arte & Mestre & $\begin{array}{l}\text { EBTT (atua também como } \\
\text { profa 2 }{ }^{\circ} \text { ano) }\end{array}$ \\
\hline
\end{tabular}

Fonte: Hartmann, 2018 
A Seção de Apoio Pedagógico (SAP), Línguas Estrangeiras Modernas (LEM) e Educação Física (SEF) ainda possuem as disciplinas, a formação e o perfil dos docentes que está constituído conforme apresentado no Quadro 10.

Quadro 10: Docentes em Seções de Ensino

\begin{tabular}{|l|l|l|l|l|}
\hline Seções & Disciplina & Formação & Titulação & Perfil/Militar/Civil \\
\hline SAP & Português & Português & Gradução & Sgt \\
\hline SAP & Matemática & Matemática & Mestre & Sgt \\
\hline LEM & Inglês & Inglês & $\begin{array}{l}\text { Especialista (02) } \\
\text { /Mestre (02) }\end{array}$ & QCO /EBTT \\
\hline SEF & Educação Física & Educação Física & $\begin{array}{l}\text { Especialista/ Mestre } \\
(02)\end{array}$ & $\begin{array}{l}\text { Oficiais combatentes e com } \\
\text { o curso de Educação Física } \\
\text { do Exército }\end{array}$ \\
\hline
\end{tabular}

Fonte: Hartmann, 2018

A distribuição dos perfis docentes no CMSM nas diferentes áreas do conhecimento evidenciou que existe um campo fértil para promover uma série de medidas que contribuam para integrar as práticas docentes e, principalmente, promover as habilidades existentes em cada perfil. A pluralidade permite identificar professores bem mais abertos às novas demandas de seu tempo, aos novos sujeitos sociais, aos novos temas curriculares e aponta para o caminho de encontro com o novo aluno, contemporâneo, imerso na atual sociedade de instabilidade, relatividade e fluidez.

Ressalta-se ainda que essa possibilidade de convivência/formação entre os diferentes perfis docentes, em momento algum, pode deixar em segundo plano o aluno, pois é indispensável segundo Tardif (2007, p. 39), “desenvolver um saber prático baseado em sua experiência cotidiana com os alunos".

\section{CONSIDERAÇÕES FINAIS}

Dessa forma, percebe-se que os colégios militares possuem, em seu corpo docente, diversos perfis docentes, que vêm se ampliando e diversificando no decorrer do tempo e que convivem sob as mesmas diretrizes pedagógicas.

No entanto, esses diferentes perfis, com planos de carreira e expectativas diferenciadas, permitem que ocorra uma interligação de saberes e conhecimentos diferenciados, bem como um dos princípios fundamentais dentro da profissão docente que é a formação na própria prática dentro da Escola. Como consequência, é possível que o convívio entre os diferentes perfis possa, mesmo que em alguns momentos, criar conflitos e tensões, permitir processos de formação mais próximos da realidade, pois o gerenciamento de 
conflitos, a capacidade de adaptação e a superação de momentos de instabilidade são hoje inerentes ao trabalho docente.

Portanto, em um Sistema de Ensino consolidado, como o SCMB, cujo sucesso está diretamente ligado à qualificação de seus professores, o reconhecimento da necessidade de que haja constantes oportunidades de aperfeiçoamento, pesquisa e produção dentro do ambiente escolar e o seu consequente incentivo são de fundamental importância para que os professores estejam preparados a enfrentar o cenário atual de constantes mudanças tanto no espaço escolar como na própria sociedade.

Para tanto, saber gerenciar o trabalho e peculiaridades dos diversos perfis docentes existentes no SCMB e no caso específico do CMSM é vital para que a diversidade se reflita em qualidade no ensino e oportunidades para formação dos professores na prática diária dentro da escola. E, nesse sentido, é necessária sempre a transparência e o diálogo para que as diferenças formativas não sejam motivos de desunião, mas sim oportunidades de construção de saberes.

\section{REFERÊNCIAS}

BATISTA, Aline Cleide; ARAGÃO, Ana Lúcia A. Profissão professor: um diálogo acerca das possibilidades e desafios. In: IV ENCONTRO DE PESQUISA EM EDUCAÇÃO DA UFPI. Universidade Federal do Piauí, 2006. Anais... Disponível em: http://leg.ufpi.br/subsiteFiles/ppged/arquivos/files/ eventos/2006.gt1/GT1_20_2006.PDF. Acesso em: 02 nov. 2017.

BENVENUTTI, Leonardo Mateus. Formação identitária docente: caminhos do ser mais. In: ROSSMANN, Márcia A.; BENVENUTTI, Leonardo Mateus; FACENDA, Luisa Cadorim (Orgs.). Dimensão(ões) da prática docente nas licenciaturas: constituição identitária e leituras de Paulo Freire. Passo Fundo: Méritos, 2014.

BRASIL. Comando do Exército. Portaria $n^{\circ}$ 291. Aprova as Instruções Gerais para o Ingresso e a Carreira do Pessoal Docente Civil do Exército incluso no Plano Único de Classificação e Retribuição de Cargos e Empregos - IG 60-01. 2005.

BRASIL. Normas de Planejamento e Gestão Escolar. Rio de Janeiro: DEPA, 2017.

BRASIL. Estatuto dos Militares. Lei no 6.880, de 9 de dezembro de 1980. Disponível em: http://www.planalto.gov.br/ccivil_03/leis/L6880.htm. Acesso em: 02 jul. 2017.

BRASIL. Boletim do Exército. Brasília, n.40, 06 out. 2017. Disponível em: www.sgex.eb.mil.br/sistemas/be/copiar.php?codarquivo=1546\&act=bre. Acesso em: 06 nov. 2017.

BRASIL. Lei $n^{o} 7831$, de 2 de outubro de 1989. Disponível em: http://www. planalto.gov.br/ccivil_03/leis/1989_1994/L7831.htm. Acesso em: 06 nov. 2017. (Página 12) 
DE PAULO, Jacks Richard. A complexidade da formação de professores de geografia e reflexos na prática de ensino. In: DE PAULO, Jacks Richard (Org.). A formação de professores de geografia: contribuições para mudança de concepção de ensino. Jundiaí: Paco, 2016.

FERRY, Gilles. Pedagogia de la formación. Buenos Aires: Centro de Publicaciones y Material didático, 2004.

FREIRE, Paulo. Pedagogia da autonomia: saberes necessários à prática educativa. São Paulo: Paz e Terra, 1996.

\section{Pedagogia do oprimido. São Paulo: Paz e Terra, 1987.}

HARTMANN, Emerson. O ensino de humanidades e as práticas docentes no Colégio Militar de Santa Maria - RS. 2018. 149f. Dissertação (Mestrado Acadêmico em Ensino de Humanidades e Linguagens) - Universidade Franciscana, Santa Maria - RS.

HARTMANN, Emerson; BECKER, Elsbeth Léia Spode. Ensino de humanidades e a prática docente no Colégio Militar de Santa Maria- RS. In: XXI SIMPÓSIO DE ENSINO, PESQUISA E EXTENSÃO- SEPE, 2017, Santa Maria. Anais... UNIFRA, 2017. p.74-75.

LELIS, Isabel. A construção social da profissão docente no Brasil: uma rede de histórias. In: TARDIF, Maurice; LESSARD, Claude (Orgs.). O ofício de professor: história, perspectivas e desafios internacionais. Petrópolis: Vozes, 2008

LIBÂNEO, José Carlos. As teorias pedagógicas modernas revisitadas pelo debate contemporâneo na educação. In: LIBÂNEO, José Carlos; SANTOS, Akiko (Orgs). Educação na era do conhecimento em rede e transdisciplinaridade. Campinas: Alínea, 2010.

LIMA, Maria do Socorro; GOMES, Marineide Oliveira. Redimensionando o papel dos profissionais de educação: algumas considerações. In: PIMENTA, Selma Garrido; GHEDIN, Evandro (Orgs). Professor reflexivo no Brasil: gênese e crítica de um conceito. São Paulo: Cortêz, 2012.

MONTEIRO, A. Reis. Profissão docente: profissionalidade e autorregulação. São Paulo: Cortez, 2015.

NOGARO, Arnaldo; CERUTTI, Elisabete. As TICs nos labirintos da prática educativa. Curitiba: CRV, 2016.

NÓVOA, António. Desafios do trabalho do professor no mundo contemporâneo. São Paulo: SINPRO, 2007.

NÓVOA, António. Para uma formação construída dentro da profissão, 2009. Disponível em: http://www.revistaeducacion.educacion.es/re350/re350_09por. pdf. Acesso em: 30 out. 2017.

NÓVOA, António (Org.). Profissão professor. Porto: Porto, 2014.

NÓVOA, António. Os professores na virada do milênio: do excesso de discursos à pobreza das práticas. Cuadernos de Pedagogía. Barcelona, n.286, p.102-108, dez.1999. 
RAUBER, Pedro. Profissão professor: exigências atuais de uma análise. Revista Jurídica UNIGRAN. Dourados, v.6, n.11, p.213-223, jan./jul. 2004.

TARDIF, Maurice. Saberes docentes e formação profissional. Petrópolis: Vozes, 2007.

ZEICHNER, Kenneth. A formação reflexiva dos professores: ideias e práticas. Lisboa: EDUCA, 1993.

\section{SOBRE OS AUTORES}

Emerson Hartmann é mestre em Ensino de Humanidades e Linguagens pela Universidade Franciscana e graduado em Geografia pelo Centro Universitário Franciscano. Possui especializações em supervisão escolar pela UFRJ, Aplicações Complementares às Ciências Militares - Educação pela EsFCEx e Conhecimentos Militares pela ESAO. É oficial do Quadro Complementar do Exército, coordenador de ano e professor de Geografia do Colégio Militar de Santa Maria - CMSM.

Elsbeth Léia Spode Becker é doutora em Agronomia pela Universidade Federal de Santa Maria, com mestrado em Engenharia Agrícola e graduação em Geografia por esta mesma instituição. É docente e pesquisadora do curso de Mestrado em Ensino de Humanidades e Linguagens da Universidade Franciscana - UFN 